\title{
Technical feasibility of integration of renewable energies in the EU
}

\author{
Marta Szabo $^{* 1}$ \\ Renewable Energies Unit - Institute for Energy (IE) \\ European Commission - Joint Research Centre (JRC), Ispra, Italy \\ * Corresponding author. Tel: +39 033278 3882, E-mail: marta.szabo@ec.europa.eu
}

\begin{abstract}
According to the Article 4(3) of Directive 2009/28/EC on the promotion of the use of energy from renewable energy sources the EU Member States submitted their forecast documents. The analysis of the forecast documents resulted that the EU will exceed the $20 \%$ renewable energy consumption target with $0,3 \%$ in 2020. The paper gives an overview about the technical feasibility of the integration of the renewable energy sources in the energy systems in the EU and analyze the critical factors and possible solutions.
\end{abstract}

Keywords: EU Renewable Energy, Integration, National Renewable Energy Action Plan

\section{Introduction}

In accordance with Article 4(3) of Directive 2009/28/EC and of the Council of 23 April 2009 on the promotion of the use of energy from renewable sources each Member States shall adopt a National Renewable Energy Action Plan. The MS-s had to submit them to the Commission by 30 June 2010 using a template according to the Commission Decision of 30 June 2009.

In the national renewable energy action plans each member state has to set the national targets for the share of energy coming from renewable energy sources consumed in electricity, heating and cooling, and transport sector as well in every second year up to 2020; taking into account the effect of energy efficiency related measures on final consumption of energy compared to the indicative trajectory. The member states announce the excess or deficit production which can be used in the cooperation mechanism or in the statistical transfer.

However, each member state has its own different technical, environmental, economic and political situation to consider in meeting its commitments. Cost competitive production of renewable energy and the system by which it reaches are key issues in establishing a viable market. Besides competitiveness, another important issue is security of supply, and a mechanism should be created for resource adjustment at a European level. This could be achieved through international partnerships and contracts, and possibly by establishing adequate storage capacity.

On the subject of environmental protection, emissions trading might prove helpful. Whether competitiveness, environmental protection or security is perceived as having the greatest priority will depend on the circumstances of the specific state. Programs in most of the EU Member States promote a reduction in energy consumption and increase energy efficiency. With a move away from traditional energy sources, the demand for power can only be met by a corresponding increase in energy generation from renewable sources. The main questions are: how realistic are the goals and what potential domestic energy resources can be exploited? What are the main drivers and barriers - mainly from technical point of view - of the integration of renewable energy sources in the energy systems? 


\section{Methodology}

The Directive 2009/28/EC on the promotion of the use of energy from renewable energy sources requires Member States to adopt a National Renewable Energy Action Plan (NREAP) and to submit to the European Commission by 30 June 2010 using a template in accordance with Article 4 of the Directive [1]. Previously all Member States have prepared their forecast documents [2] and submitted them in accordance with the Article 4(3) of the Directive.

The forecast documents indicated the estimated excess production from renewable energy sources compared to the indicative trajectory which could be transferred to the other Member States and the estimated demand for energies from renewables to be covered by means other than domestic production until 2020. It had to be stated also how big is the estimated potential for joint projects until 2020.

Comparative and summary analysis has been executed in order to see the size and the ability of the contribution of the Member States from the forecast documents and national and European project reports [3, 4].

\section{Results}

Most of the EU Member states are optimistic on the way to meet their target from only domestic action and resources. The forecast documents of the Member States resulted that the EU in 2020 will exceed the 20 \% Renewable Energy consumption target with 0,3 \%. From the forecast analysis it can be expected also that the EU will reach a net surplus also in the interim period until 2020 probably each year as it is presented in the Figure 1.

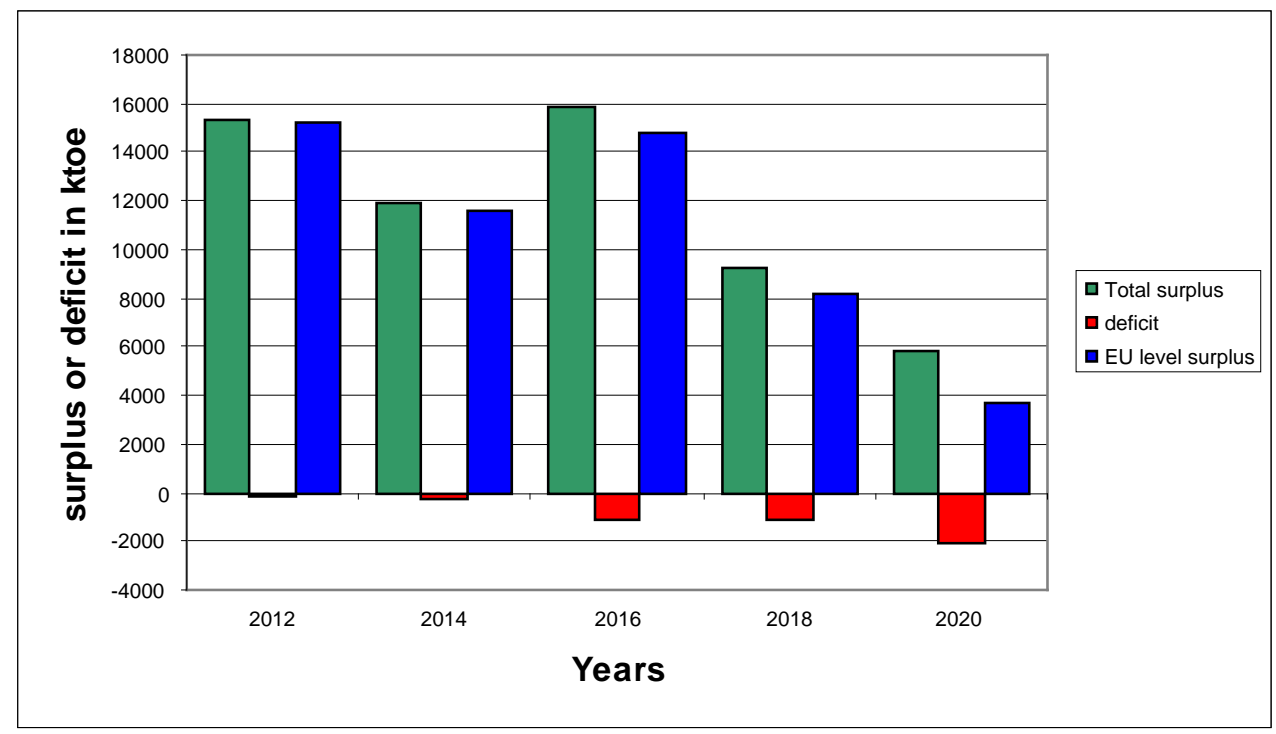

Fig. 1. The RES surplus or deficit between 2010 an 2020 in the EU27.

\subsection{Energy consumption Scenarios}

The Member States prepared their forecast taking into account the Additional energy efficiency scenario and many Member States emphasized that the projected targets can be reached only applying the energy efficiency measures. 
The main renewable energy resources are biomass, hydro and wind. The majority of the Member States announced biomass as the main renewable energy resource, some of them emphasized also hydro energy and wind energy.

9 Member states announced surplus by the year 2020 as it is presented in Figure 2. The highest surplus in absolute term has Germany and Spain with 1387 and 2700 ktoe respectively.

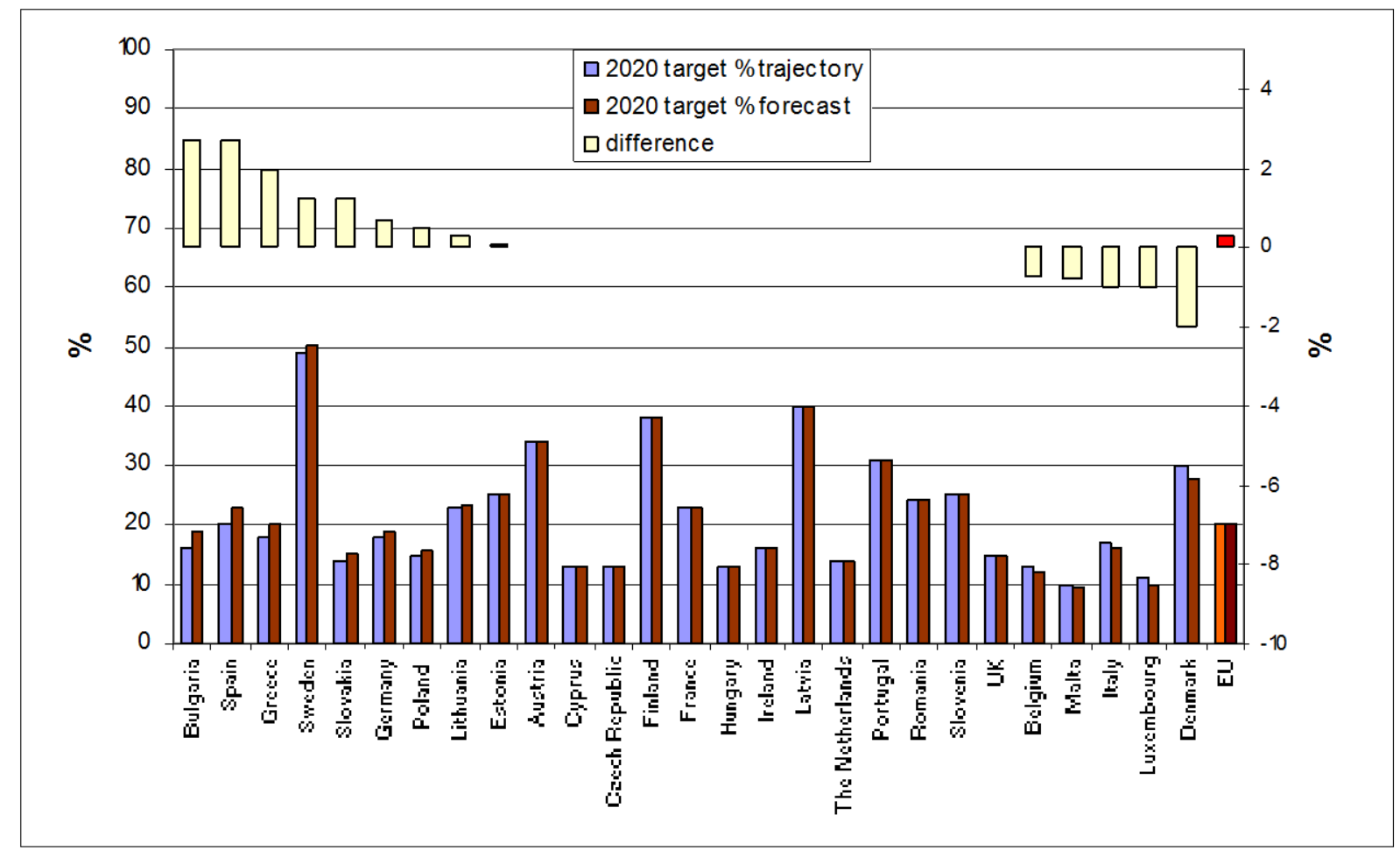

Fig. 2. The indicative and forecasted share of the Renewable Energies in the EU 27 by 2020

5 Member states forecasted deficit in 2020, Italy has the highest absolute deficit with a -1170 ktoe $(-1 \%)$.

The member states can use cooperation mechanisms to help with their surplus or meet their deficit. 13 member states are willing to use the Joint projects, and 8 to use the statistical transfer. Wind and biomass are the most involved resource in the joint projects in power generation using the existing electricity links in the Balkan area.

\subsection{Sectorial use break down}

Some Member States already provided forecast on the sectorial breakdown of the RES development until 2020. Among these countries the highest share had the renewable electricity and also heating and cooling represented a big proportion, as it is demonstrated in the Figure 3. 

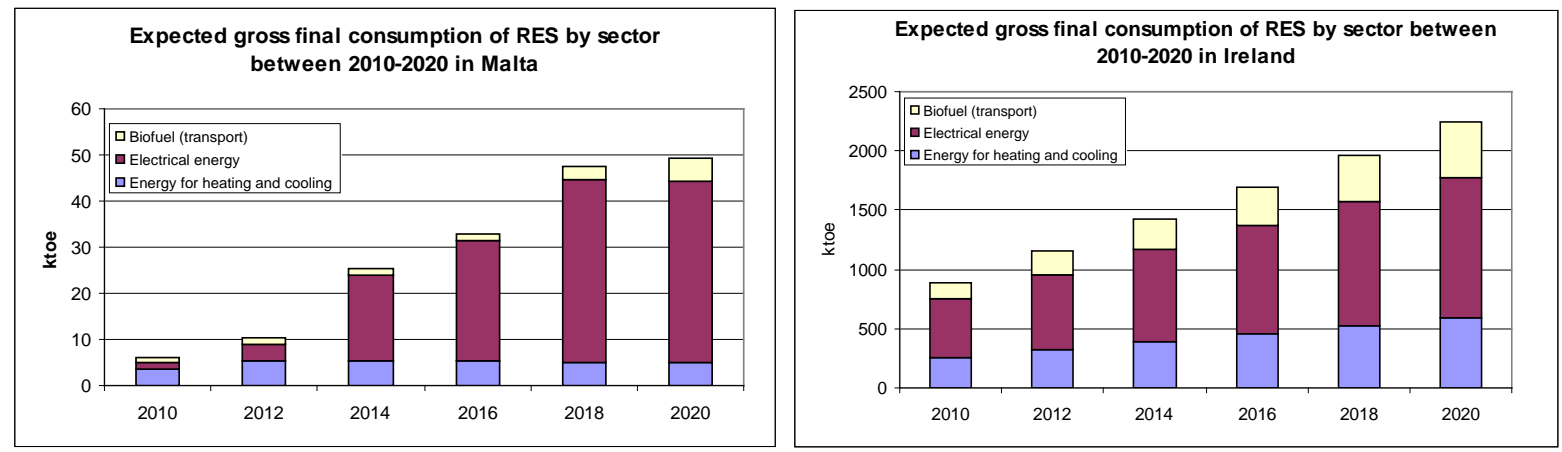

Fig. 3. Forecasted sectorial breakdown of RES final consumption in some member states

Many of the Member States raised critical factors which are barriers in reaching the targets or which need development in order to achieve a better performance of the targets. Among the obstacles countries mentioned their isolated geographical situation and restrictions in interconnection capacity; thus they expressed the need of development in interconnections.

Regional differences appear from the recourse aspects and also in the energy use. Countries like Italy and Greece have a high PV potential, high air conditioning penetration but have high summer peaks, and countries like France or Bulgaria have high level of electrical heating and lower PV potential but low summer peaks.

However it is a good potential of offshore wind resource, the implementation depends mainly on the development of infrastructure for integration wind energy to the grid.

Solar energy has the highest potential in terms of availability, with daily and seasonal variation in different geographical location. There is an expressed need for flexibility of grid management and of generation mix. The advantages of PV are that it can provide peak power and can be used in the decentralized electricity; this means reduction of network losses. Grid electricity losses are proportional to the distance between the points of generation and use, so as PV is a distributed and decentralized source it needs shorter transmission route.

The integration of wind and biomass could help increase the predictability, in the storage and in the simultaneity aspects, although wind and PV require the same measures in the grid development. PV is easier to forecast and less impacted by local topography, wind has higher energy density and its integration into the grid is more similar to that of conventional concentrated generation.

General need is the modernization of electrical grids, the reinforcement of grid infrastructure and electricity interconnection and also the offshore wind development. As the share of RES electricity from renewable is around $35 \%$ in the EU there is a general need to improve the stability of the European electricity grid which requires new infrastructure. There is no harmonized method for transmission planning over the EU Countries and there is a lack of harmonization of the grid connection rules of wind plans

There are inconsistencies in regulations of the transmission planning, i.e. there are different policies in different countries; RES has not the same priority in all countries, the related grid expansion costs are shared differently and not always in transparent way. There is inconsistency in the technical requirements and the separation of generation, transmission and retail services complicates the process. 


\section{Conclusions}

The system integration challenges are dependent of several factors like the energy resource (location, potential, technical development), technology and the technological development of the system components (from the production through the transformation, storage, distribution system, interconnection capacities, etc.).

The biggest challenges appear in the electricity as the main form of the energy integration. The penetration of PV, wind and bioelectricity is highly dependent on the system flexibility. In the different EU member states the different transmission and distribution grids means a kind of barrier, and as it was formulated already in the forecast documents the grid infrastructure needs to be reinforced and requires new infrastructure at generation, at transmission and also at distribution level. An integrated European grid needs harmonized codes, policies, regulations and technical standards; as well an improvement in the transmission planning method. With these measures the indicative targets can be achieved.

\section{References}

[1] European Commission 2009 Directive 2009/28/EC on the promotion of the use of energy from renewable energy sources. Official Journal of the European Communities/L $140 / 16 /$.

[2] Renewable energy forecast documents. Available online on the Commission Transparency Platform, established in conformity with Article 24 of the Directive. 2010: http://ec.europa.eu/energy/renewables/transparency_platform/forecast_documents_en.ht $\underline{\mathrm{m}}$

[3] EUROSTAT, 2010. statistic Database: Energy

[4] Szabó, M. 2009. Perspectives on Renewable Energy Sources in Hungary. Renewable Energy 2009. Global regional Outlook. Sovereign Publications, London. p. 129-131.

\footnotetext{
${ }^{1}$ The views expressed in this paper are those of the authors and do not necessarily represent European Commission policy.
} 